\title{
Preparation of Carboxymethyl-chitin Nanoparticles by Covalent Crosslinking and Their In Vitro Evaluation
}

\author{
Hiraku Onishi", Kota Kume, Ken-ichi Koyama and Yoshiharu Machida
}

Department of Drug Delivery Research, Hoshi University, 2-4-41, Ebara, Shinagawa-ku, Tokyo 142-8501, Japan

\begin{abstract}
The degree of deacetylation and molecular weight of carboxymethyl-chitin (CM) were manipulated using $10 \%$ (w/v) $\mathrm{NaOH}$ aqueous solution at $25^{\circ} \mathrm{C}$ and $5 \mathrm{M} \mathrm{HCl}$ aqueous solution at $40^{\circ} \mathrm{C}$, respectively. The resultant $\mathrm{CMs}$ were characterized by ${ }^{1} \mathrm{H}-\mathrm{NMR}$ spectroscopy and size exclusion chromatography/multi-angle light scattering. The degree of deacetylation of $7-35 \%(\mathrm{~mol} / \mathrm{mol})$ and molecular weight of 43,000 - 449,000 were achieved. Nanoparticles were prepared using W/O emulsification and amide coupling. Nanoparticles with the size of less than $400 \mathrm{~nm}$ were obtained using CM with a high degree of deacetylation and low molecular weight, CM48-L. When the mixture of CM-mitomycin C conjugate and CM48-L underwent W/O emulsification and amide coupling, nanoparticles with the size of ca. 350 nm were obtained, and released mitomycin $\mathrm{C}$ fairly fast but gradually. $\mathrm{CM}$ with a high degree of deacetylation and low molecular weight was suggested to be useful for the production of CM nanoparticles.
\end{abstract}

Keywords: Carboxymethyl-chitin nanoparticles, crosslinking, deacetylation, molecular weight, mitomycin C.

\section{INTRODUCTION}

Chitin and chitosan have drawn much attention in many fields including medicine, pharmaceuticals, agriculture because of their biocompatibility, biodegradability and low cost [1-3]. Since they are neither soluble in neutral aqueous solution nor many organic solvents, their handling and processing are not easy. As chitosan is soluble in acidic aqueous solution, micro- or nanoparticles of chitosan have been produced by techniques such as emulsification and precipitation $[1,4,5]$. Chitin is much more difficult to utilize because of its much poorer solubility. One of the methods used to improve the solubility charateristics of chitin and chitosan is chemical modification. Many derivatives of chitin and chitosan have been developed recently [6-8].

$\mathrm{N}$-Succinyl-chitosan (SUC) and carboxymethyl-chitin (CM) are well-known as water-soluble derivatives of chitosan and chitin, respectively $[9,10]$. They are soluble in aqueous solutions of acidic, neutral and basic $\mathrm{pH}$, and have very low toxicity $[11,12]$. These derivatives have been utilized as drug carriers in drug delivery systems such as macromolecule-drug conjugates or microparticles [13, 14]. Since these polymers have carboxy groups as reactive moieties, drugs with amino groups can be easily combined with them by forming amide bonds. The conjugates of mitomycin $\mathrm{C}$ (MMC) with SUC and CM were obtained by coupling with 1-ethyl-3-(3-dimethylaminopropyl)-carbodiimide hydrochloride (EDC) $[13,14]$. These conjugates acted as macromolecular prodrugs of MMC [13]. In the preparation of these conjugates, they were precipitated, dependent on the degree of deacetylation of the polymers $[13,14]$. Since SUC and $\mathrm{CM}$ have a few amino groups in addition to carboxy groups, they can undergo crosslinking to one another with amide coupling reagents, resulting in precipitation of the conjugates.

*Address correspondence to this author at the Department of Drug Delivery Research, Hoshi University, 2-4-41, Ebara, Shinagawa-ku, Tokyo 142-8501, Japan; Tel.: +81-3-5498-5724; Fax: +81-3-3787-0036;

E-mail: onishi@hoshi.ac.jp
Thus, SUC-MMC conjugate particles and CM-MMC conjugate particles were prepared by coupling with EDC. Both particles were found to have a size of $4.1 \mu \mathrm{m}$ and $7.1 \mu \mathrm{m}$, respectively [14]. In order to obtain soluble conjugates after EDC condensation, it seemed to be needed to derivatize amino groups completely in advance. In addition, microparticules $(\mathrm{CM}-\mathrm{Fe}(\mathrm{III}))$ could be prepared by complexation of $\mathrm{CM}$ and $\mathrm{Fe}(\mathrm{III})$ ion [15]. CM-Fe(III) showed the mean size of $1-2 \mu \mathrm{m}$, though some of them had the size of several hundred nm [15]. Furthermore, the preparation of micro- or nanoparticles of SUC or CM conjugate was attempted by a combination of $\mathrm{W} / \mathrm{O}$ emulsification and sonication. In this method, SUC-MMC conjugate particles with the size of several hundred nm size could be obtained. CM-MMC conjugate particles were prepared in a similar manner, but they showed a size of approximately $1 \mu \mathrm{m}$ even using CM with a low molecular weight and high degree of deacetylation [16]. Therefore, the preparative conditions for forming CM-drug conjugate nanoparticles need to be studied in order to achieve the size range of several hundred $\mathrm{nm}$ or less. Nanoparticles with a size of a few hundred $\mathrm{nm}$ or less are more useful because they tend to accumulate in solid tumors due to enhanced permeability and retention (EPR) effect [17, 18]. In the conjugate particles, the particle size appeared to be dependent on the polymer properties such as degree of deacetylation and molecular weight $[14,16]$. Thus, in this study, attempts were made to investigate in more detail the possibility of producing CM nanoparticles via crosslinking using several kinds of CMs with differing degrees of deacetylation and molecular weights. Finally, the method was applied to the preparation of $\mathrm{CM}$ nanoparticles loaded with MMC.

\section{MATERIALS AND METHODOLOGY}

\section{Materials}

Original CM was supplied by Ichimaru Pharcos Co. Ltd., and named CM0-H. MMC was extracted by methanol from Mitomycin Kyowa S purchased from Kyowa Hakko Kogyo, Co. (Japan), and used after drying in vacuo. EDC was pur- 
chased from Dojindo laboratories (Kumamoto, Japan). Sorbitan sesquioleate (SO-15) was obtained from Nikko Chemicals Co., Ltd. (Tokyo, Japan).

\section{Deacetylation of CM}

CM0-H, original CM, $(1 \mathrm{~g})$ was dissolved in $100 \mathrm{~mL}$ of $10 \%(\mathrm{w} / \mathrm{v}) \mathrm{NaOH}$ aqueous solution, and stirred at $25^{\circ} \mathrm{C}$ for 48 or $72 \mathrm{~h}[15,19]$. Then, the $\mathrm{pH}$ of the solution was adjusted to 8 by addition of $5 \mathrm{M} \mathrm{HCl}$ aqueous solution, and poured into $1.6 \mathrm{~L}$ of the mixture of acetone and water $(8: 1$, $\mathrm{v} / \mathrm{v})$ to precipitate the product. The precipitate was taken by the filtration, and washed with the mixture of acetone and water $(8: 1, \mathrm{v} / \mathrm{v})$. The precipitate was re-dissolved in $120 \mathrm{~mL}$ of water, dialyzed against water using a Seamless Cellulose Tubing (molecular weight cut off limit 14,000; Sanko Junyaku Co., Ltd., Japan), and lyophilized to obtain a powder of $\mathrm{CM}$ with a higher degree of deacetylation. The $\mathrm{CM}$ obtained by the treatment with $\mathrm{NaOH}$ for $\mathrm{x}(\mathrm{h})$ was abbreviated to CMx.

\section{Reduction of Molecular Weight of CM}

$\mathrm{CMx}, \mathrm{CM}$ with a different degree of deacetylation, was dissolved in $5 \mathrm{M} \mathrm{HCl}$ aqueous solution, and stirred at $40^{\circ} \mathrm{C}$

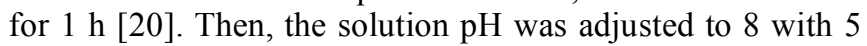
$\mathrm{M} \mathrm{NaOH}$ aqueous solution. The resultant solution was dialyzed as stated above, and lyophilized to obtain a powder of $\mathrm{CM}$ with reduced molecular weight. CMxs before and after degradation with $\mathrm{HCl}$ were named $\mathrm{CMx}-\mathrm{H}$ and $\mathrm{CMx}-\mathrm{L}$, respectively.

\section{Characterization of CM}

${ }^{1}$ H-NMR spectrometry was performed using a JEOL JNM-LA500 spectrometer (JEOL, Tokyo, Japan). The sample was dissolved in $\mathrm{D}_{2} \mathrm{O}$ and measured at $80^{\circ} \mathrm{C}$. The signal of $H \mathrm{DO}$ in $\mathrm{D}_{2} \mathrm{O}$ was used as a standard (4.65 ppm) to read the chemical shift of each proton [21]. Molecular weights were measured by size-exclusion chromatography-multi angle light scattering (SEC-MALS) using a Wyatt Technology DAWN HELEOS (658 nm) and a Wyatt Technology Optilab rEX $(658 \mathrm{~nm})$ as a multi-angle light scattering detector and differential refractive index detector, respectively [20, 22]. The Shodex SB-806 M was used as an analytical column. The mobile phase was $0.05 \mathrm{M}$ phosphate buffer, $\mathrm{pH} 7.0$, and was eluted at a rate of $1 \mathrm{~mL} / \mathrm{min}$. The refractive index increment $(\mathrm{dn} / \mathrm{dc})$ was measured in $0.05 \mathrm{M}$ phosphate buffer, $\mathrm{pH} 7.0$, using a Wyatt Technology Optilab rEX $(658 \mathrm{~nm})$.

\section{Preparation of CM Nanoparticles by Simple Crosslinking}

CMx-H or CMx-L $(30 \mathrm{mg})$ was dissolved in $5 \mathrm{~mL}$ of water, and dripped into $75 \mathrm{~mL}$ of n-heptane with $2 \%(\mathrm{w} / \mathrm{v})$ SO-15, which had been cooled with iced water in advance. After the mixture was emulsified by stirring at $600 \mathrm{rpm}$ for 10 min with sonication set at $28 \mathrm{kHz}(100 \mathrm{~W}), 1 \mathrm{~mL}$ of EDC aqueous solution $(100 \mathrm{mg} / \mathrm{mL})$ was added, and stirring $(600$ $\mathrm{rpm})$ with sonication $(28 \mathrm{kHz})$ was performed for $30 \mathrm{~min}$. Furthermore, $1 \mathrm{~mL}$ of $\mathrm{CH}_{3} \mathrm{COONH}_{4}$ aqueous solution (300 $\mathrm{mg} / \mathrm{mL}$ ) was added, and the mixture was stirred at $600 \mathrm{rpm}$ for $10 \mathrm{~min}$ with sonication set at $28 \mathrm{kHz}(100 \mathrm{~W})$. The mixture was centrifuged at $5000 \mathrm{rpm}$ for $20 \mathrm{~min}$. The precipitate was washed first with methanol and then with water. Finally, the precipitate was suspended in water to obtain the aqueous suspension of CM nanoparticles.

\section{Preparation of CM Nanoparticles Loaded with MMC}

Thirty milligrams of $\mathrm{CM}$ with a molecular weight of 51,000 and deacetylation degree of $17 \%$ (CM0-L) was dissolved in $2 \mathrm{~mL}$ of water, and $2 \mathrm{~mL}$ of MMC aqueous solution $(2.5 \mathrm{mg} / \mathrm{mL})$ and $1 \mathrm{~mL}$ of EDC solution $(100 \mathrm{mg} / \mathrm{mL})$ were added. After the $\mathrm{pH}$ of the mixture was adjusted to 6 , the mixture was stirred for $2 \mathrm{~h}$, and chromatographed with a Sephadex G50 column using water as an elution solvent to separate the CM-MMC conjugate (CM-MMC). CM-MMC was washed by ultrafiltration (molecular weight cut off limit $10,000)$, and lyophilized to form a powder.

The CM/CM-MMC mixture nanoparticles, named MMC-NP, were prepared by the carbodiimmide coupling with EDC (Fig. 1). CM with a molecular weight of 76,000 and degree of deacetylation of 33\% (CM48-L) and CM-MMC were mixed in $4 \mathrm{~mL}$ of water at a ratio of $1 / 1,1 / 2$ or $1 / 5(\mathrm{w} / \mathrm{w})$ with a total weight of $30 \mathrm{mg}$. Each solution was dripped into $75 \mathrm{~mL}$ of $\mathrm{n}$-heptane containing $2 \%(\mathrm{w} / \mathrm{v})$ SO-15, which had been cooled with iced water in advance. The mixture was emulsified by stirring at $600 \mathrm{rpm}$ for 10 min with sonication at $28 \mathrm{kHz}(100 \mathrm{~W})$. After $1 \mathrm{~mL}$ of EDC aqueous solution $(100 \mathrm{mg} / \mathrm{mL})$ was added, stirring (600 rpm) with sonication $(28 \mathrm{kHz})$ was conducted for $30 \mathrm{~min}$. Then, 1 $\mathrm{mL}$ of $\mathrm{CH}_{3} \mathrm{COONH}_{4}$ aqueous solution $(300 \mathrm{mg} / \mathrm{mL})$ was added, and the mixture was stirred at $600 \mathrm{rpm}$ for $10 \mathrm{~min}$ with sonication at $28 \mathrm{kHz}(100 \mathrm{~W})$. The mixture was centrifuged at $5000 \mathrm{rpm}$ for $20 \mathrm{~min}$. The precipitate was washed first with methanol and then with water. Finally, the precipitate was suspended in water to obtain the aqueous suspension of MMC-NP. MMC-NP obtained with the $\mathrm{CM} / \mathrm{CM}-\mathrm{MMC}$ ratios of $1 / 1,1 / 2$ and $1 / 5$ were named MMC-NP(1), MMC-NP(2) and MMC-NP(3), respectively.

\section{In Vitro Analysis of Nanoparticles}

The size of the nanoparticles was measured by dynamic light scattering of the aqueous suspension using a laser light-scattering instrument, ELS-800, (Otsuka Electronic Co., Ltd., Tokyo, Japan), in which photon correlation was adopted as an analytical method. The drug content of MMC-NP was determined as follows. The $\mathrm{pH}$ of the aqueous suspension of MMC-NP was adjusted to 9 using a $1 / 15 \mathrm{M}$ phosphate buffer, and heated at $85^{\circ} \mathrm{C}$. At regular time points, the samples were withdrawn, and filtered with an ultrafilter (molecular weight cut off limit 100,000). The amount of MMC in the filtrate was measured by HPLC. The drug content was determined from the maximum amount of $\mathrm{MMC}$ filtered out. The release of MMC from MMC-NP was performed as follows. After aqueous suspension of MMC-NP was divided into each glass tube $(0.3 \mathrm{~mL}), 1.2 \mathrm{~mL}$ of $1 / 15 \mathrm{M}$ phosphate of $\mathrm{pH} 7.4$ was added to each tube, mixed, and incubated on the water bath at $37^{\circ} \mathrm{C}$. At $1,4,12$ and $24 \mathrm{~h}$, the tubes were taken and filtered using a ultrafilter (molecular weight cut off limit 100,000). The filtrate was analyzed for MMC by HPLC.

\section{HPLC Assay}

High-performance liquid chromatography (HPLC) was used for the assay of MMC in the samples. A Shimadzu LC-6AD equipped with a Shimadzu SPD-10AV absorbance detector $(364 \mathrm{~nm})$ and Shimdazu C-R7A plus chromatopac was used, and a Waters $\mu$-Boundapak C18 $(10 \mu \mathrm{m})$ column 


\section{$\mathbf{C M}+\mathbf{C M}-\mathbf{M M C}$}

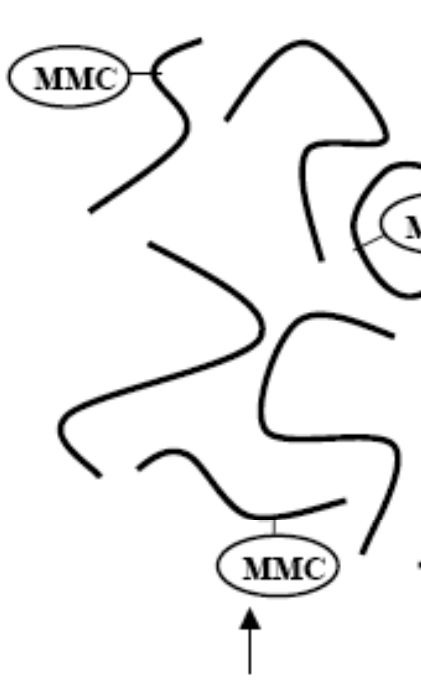

CM/CM-MMC nanoparticles

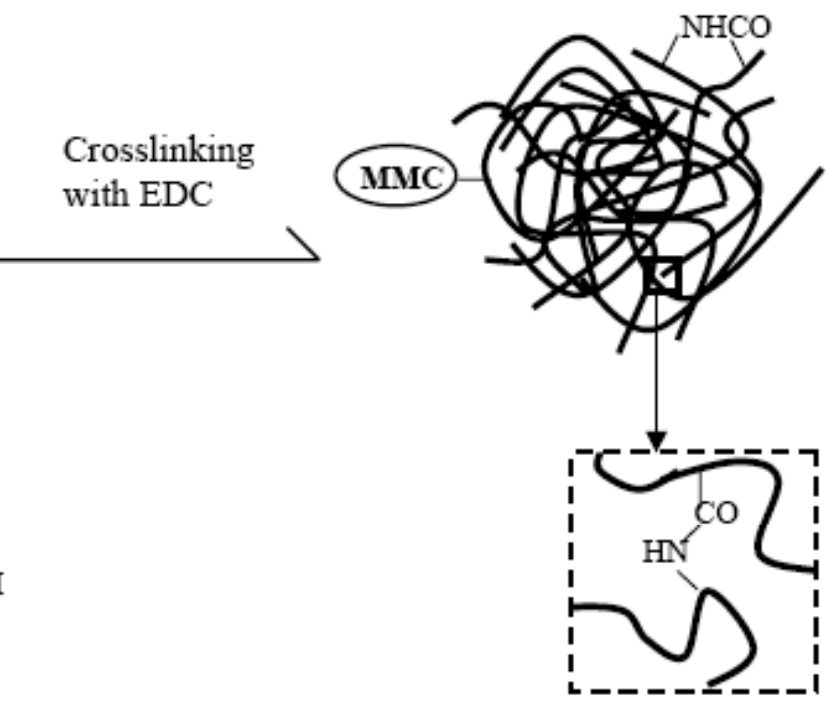

Fig. (1). Crosslinking schematic diagram for the formation of CM/CM-MMC mixture nanoparticles.

(3.9 $\mathrm{mm}$ in diameter $\times 300 \mathrm{~mm}$ in length) was used at $40^{\circ} \mathrm{C}$ in a column oven. For a mobile phase, a mixture of $1 / 15 \mathrm{M}$ phosphate buffer of $\mathrm{pH} 6.0$ and methanol $(65: 35, \mathrm{v} / \mathrm{v})$ was used, and the flow rate was set at $1.5 \mathrm{~mL} / \mathrm{min}$. The absolute calibration curve method was used for the calculation of the concentration $[13,16]$.

\section{RESULTS AND DISCUSSION}

\section{Characteristics of $\mathrm{CM}$}

The structural diagram of CM is represented in Fig. (2A). According to the supplier's specifications of the original CM $(\mathrm{CM} 0-\mathrm{H})$, it is supposed to have the carboxymethylation degree of $72 \%$ and molecular weight of $100,000-$ $1,000,000$. CM0-H was treated at $25^{\circ} \mathrm{C}$ only with $10 \%(\mathrm{w} / \mathrm{v})$ $\mathrm{NaOH}$ in order to raise the degree of deacetylation. When the treatment time was $\mathrm{x}(\mathrm{h})$, the obtained $\mathrm{CM}$ was named $\mathrm{CMx}-\mathrm{H}$. Further, treatment of $\mathrm{CMx}-\mathrm{H}$ at $40^{\circ} \mathrm{C}$ with $5 \mathrm{M} \mathrm{HCl}$ for $1 \mathrm{~h}$ was conducted for the degradation of the molecular weight. The resultant CM was named CMx-L. The ${ }^{1} \mathrm{H}-\mathrm{NMR}$ spectrum of CM72-L is shown in Fig. (2B), where chemical shifts were obtained by setting that of $H \mathrm{DO}$ as 4.65 . The degree of deacetylation was calculated by comparing the integrated intensity of 2'- $\mathrm{H}$ with that of b- $\mathrm{CH}_{3}$. The integrated intensities of the protons given by the ${ }^{1} \mathrm{H}-\mathrm{NMR}$ spectrum for CM0-H exhibited the carboxymethylation degree of approximately $70 \%$, which was almost equal to the data by the supplier. The degree of deacetylation of each obtained polymer was summarized in Table 1 . The carboxymethylation degree did not seem to be lowered by the alkaline or acidic treatment. However, the acidic treatment increased the degree of deacetylation to a small extent.

The $\mathrm{dn} / \mathrm{dc}$ values of the CMs obtained in the buffer of $\mathrm{pH}$ 7.4 were in the range of $1.4-1.7 \mathrm{~mL} / \mathrm{g}$. In the present SEC-MALS, the log (molecular weight) of the polymer eluted from the column declined almost linearly with the
(A)

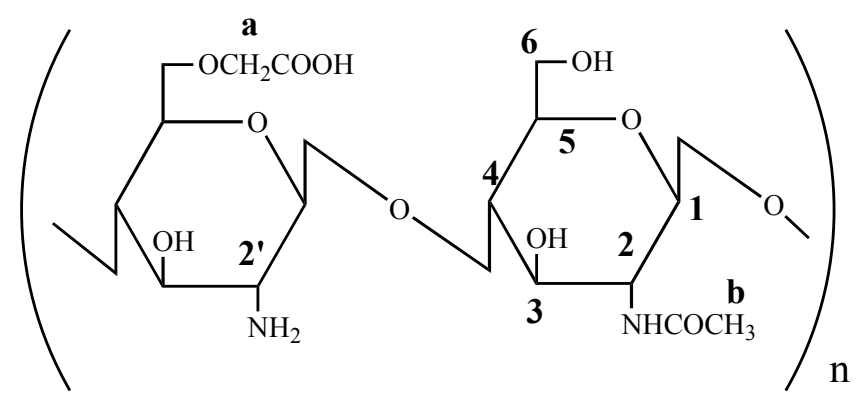

(B)

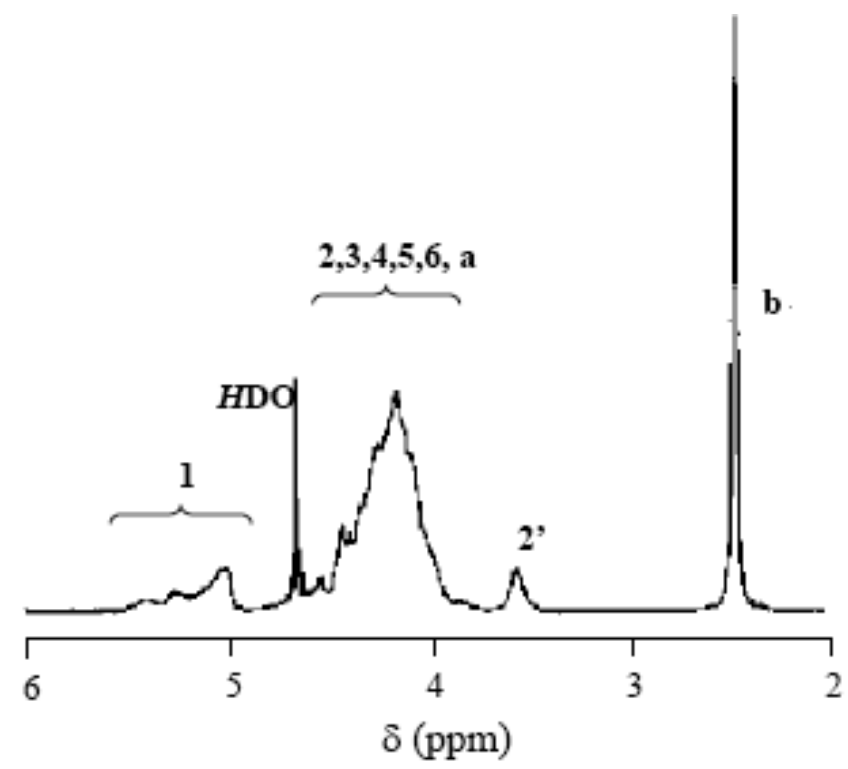

Fig. (2). Structural diagram of CM (A) and ${ }^{1} \mathrm{H}-\mathrm{NMR}$ spectrum of CM72-L (B). 
Table 1. Polymer characteristics of $\mathrm{CMs}$ Obtained by Alkaline $\left(10 \% \mathrm{NaOH}, 25^{\circ} \mathrm{C}\right)$ and Acidic $\left(5 \mathrm{M} \mathrm{HCl}, 40^{\circ} \mathrm{C}\right) \mathrm{Treatment}$

\begin{tabular}{|c|c|c|c|c|c|c|}
\hline Polymer & Alkaline treatment time (h) & Acid treatment time (h) & Degree of deacetylation $(\%, \mathrm{~mol} / \mathrm{mol})$ & Mw & Mn & Mw/Mn \\
\hline $\mathrm{CM} 0-\mathrm{H}$ & 0 & 0 & 7 & 449,000 & 228,000 & 1.56 \\
\hline CM48-H & 48 & 0 & 30 & 210,000 & 149,000 & 1.42 \\
\hline $\mathrm{CM} 72-\mathrm{H}$ & 72 & 0 & 34 & 180,000 & 122,000 & 1.48 \\
\hline CM0-L & 0 & 1 & 17 & 51,000 & 41,000 & 1.25 \\
\hline CM48-L & 48 & 1 & 33 & 76,000 & 59,000 & 1.29 \\
\hline CM72-L & 72 & 1 & 35 & 43,000 & 34,000 & 1.26 \\
\hline
\end{tabular}

Each result was obtained by a single experiment.

$\mathrm{Mw}$ and Mn represent a weight-average molecular weight and number-average molecular weight, respectively.

increase in the elution volume. This relationship was observed in the molecular weight range of 2,000,000 (elution volume of $6.0 \mathrm{~mL}$ ) $-20,000$ (elution volumeof $9 \mathrm{~mL}$ ) (data not shown). The polymer elution profiles obtained by the RI detector are shown in Fig. (3). The weight-average molecular weight $(\mathrm{Mw})$ and number-average molecular weight $(\mathrm{Mn})$ were calculated based on the SEC-MALS data as shown in Table 1. The original CM (CM0-H) had the molecular weight of 449,000 , and was degraded to some extent by the alkaline treatment as observed in CM48-H and CM72-H. The treatment by the acidic treatment reduced their molecular weight to $40,000-80,000$. The effect of the acid treatment appeared not to depend on the degree of deacetylation.

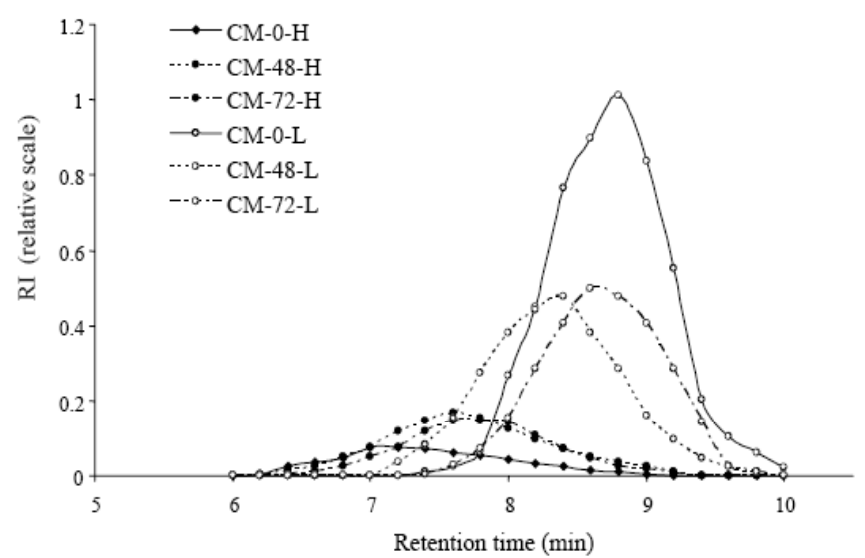

Fig. (3). Elution profiles of CMswith different molecular weights and degrees of deacetylation.

\section{Preparation and In Vitro Properties of Nanoparticles}

Nanoparticles were prepared by a combination of $\mathrm{W} / \mathrm{O}$ emulsification and simple crosslinking of the polymers with EDC. The reaction with EDC is considered mainly based on the attack of nucleophiles to a reactive intermediate, O-acylisourea [23]. Generally, reactivity with EDC is known not to be high. O-acylisourea is unstable due to undergoing an attack of water [23]. Thus, a part of carboxy groups were modified with amino groups, and other carboxy groups seem to remain with no reaction, which were found in the reports of carboxy groups-containing polymers and MMC [24, 25]. Although the reactive groups were presumed to hardly remain in nanoparticles due to its instability, excessive ammonium was added to eliminate possibly remaining activated groups; a part of carboxy groups of the final nanoparticles might be changed to the amide by the reaction of ammonium. In addition, excessive amount of $\mathrm{CH}_{3} \mathrm{COONH}_{4}$ was considered to be useful to stop the reaction between EDC and CM. The treatmemt of $\mathrm{CH}_{3} \mathrm{COONH}_{4}$ alone with EDC did not give any solid product in a similar condition, indicating nanoparticles were composed of CM-related materials. However, amidation might be caused by the additiojn of $\mathrm{CH}_{3} \mathrm{COONH}_{4}$. Therefore, the detailed structure of the nanoparticles will have to be examined in the feature. Particle size features of the resultant particles are shown in Table 2. No particles could be formed in $\mathrm{CM} 0-\mathrm{H}$ and $\mathrm{CM} 0-\mathrm{L}$. This was considered to be because of the very low content of amino groups in these polymers. When CM48-H and CM72-H were used, the resultant particles had the size of $687 \pm 70 \mathrm{~nm}$, and $1092 \pm 478 \mathrm{~nm}(\mathrm{n}=3)$, respectively. On the other hand, the nanoparticles by crosslinking of CM48-L and CM72-L showed the size of $374 \pm 159 \mathrm{~nm}$ and $426 \pm 172 \mathrm{~nm}(\mathrm{n}=3)$, respectively. These results suggested that when $\mathrm{CMs}$ with a high degree of deacetylation were used, particles with the size of one $\mu \mathrm{m}$ or less could be formed, and CMx-L should tend to give smaller particles than $\mathrm{CMx}-\mathrm{H}$. Crosslinking was considered to be formed well under the condition of high contents of amino groups. As the CMx-L aqueous solution was less viscous than $\mathrm{CMx}-\mathrm{H}$ aqueous solution, smaller droplets were formed in the $\mathrm{W} / \mathrm{O}$ emulsion, resulting in a reduced size of the particles. CM48-L was considered to be the best polymer to give smallest size of nanoparticles. The mean size of CM48-L nanoparticles, being $374 \mathrm{~nm}$, was not optimal but useful for the EPR effect.

Preparation of CM-drug conjugate nanoparticles was conducted in an similar approach. First, CM0-L-MMC conjugate (CM-MMC) was prepared by EDC condensation of

Table 2. Mean Particle Size of the Particles Produced Using CMs with Different Degrees of Deacetylation and Molecular Weights

\begin{tabular}{|c|c|c|c|c|c|c|}
\hline CM & CM0-H & CM48-H & CM72-H & CM0-L & CM48-L & CM72-L \\
\hline \hline Mean size (nm) & Not formed & $687 \pm 79$ & $1092 \pm 478$ & Not formed & $374 \pm 159$ & $426 \pm 172$ \\
\hline
\end{tabular}


Table 3. Formulations and Particle Characteristics of MMC-NP

\begin{tabular}{|c|c|c|c|c|c|}
\hline MMC-NP & CM (mg) & CM-MMC (mg) & Mean Size (nm) & Size distribution min. - max. (nm) & Drug content (\%, w/w) \\
\hline \hline MMC-NP(1) & 15 & 15 & 1660 & $50-5340$ & $-{ }^{\mathrm{a}}$ \\
\hline MMC-NP(2) & 10 & 20 & 843 & $70-2080$ & $-{ }^{\mathrm{a}}$ \\
\hline MMC-NP(3) & 5 & 25 & 346 & $180-1220$ & 3.84 \\
\hline
\end{tabular}

Each result was obtained by a single experiment.

${ }^{a}$ These were not checked because their mean size was too big to undergo the EPR effect.

(A)

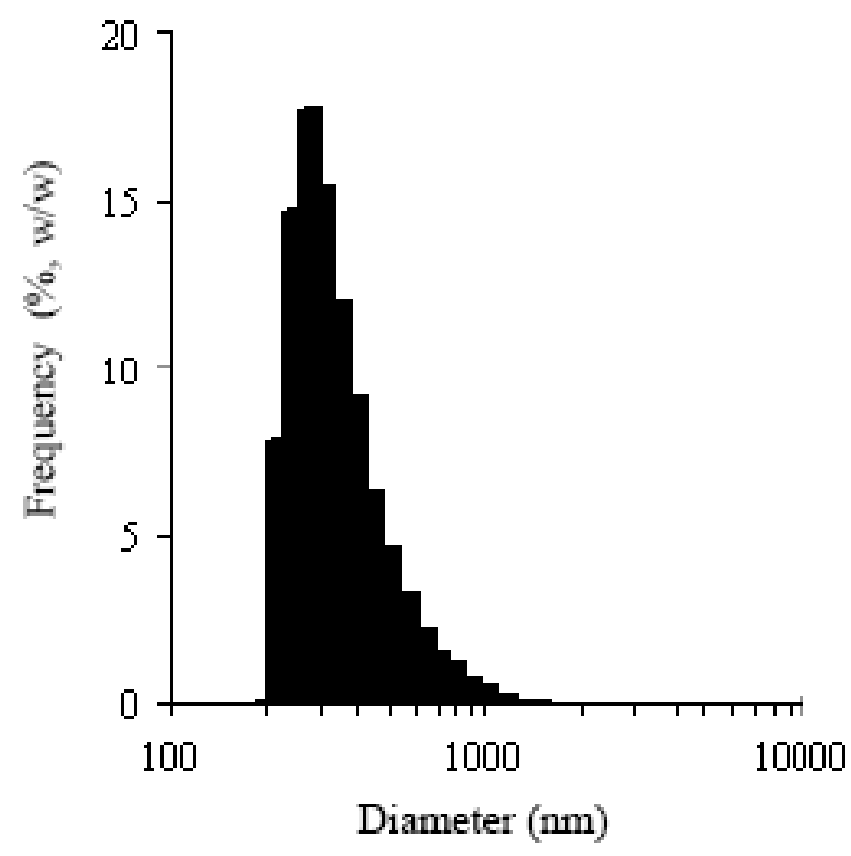

(B)

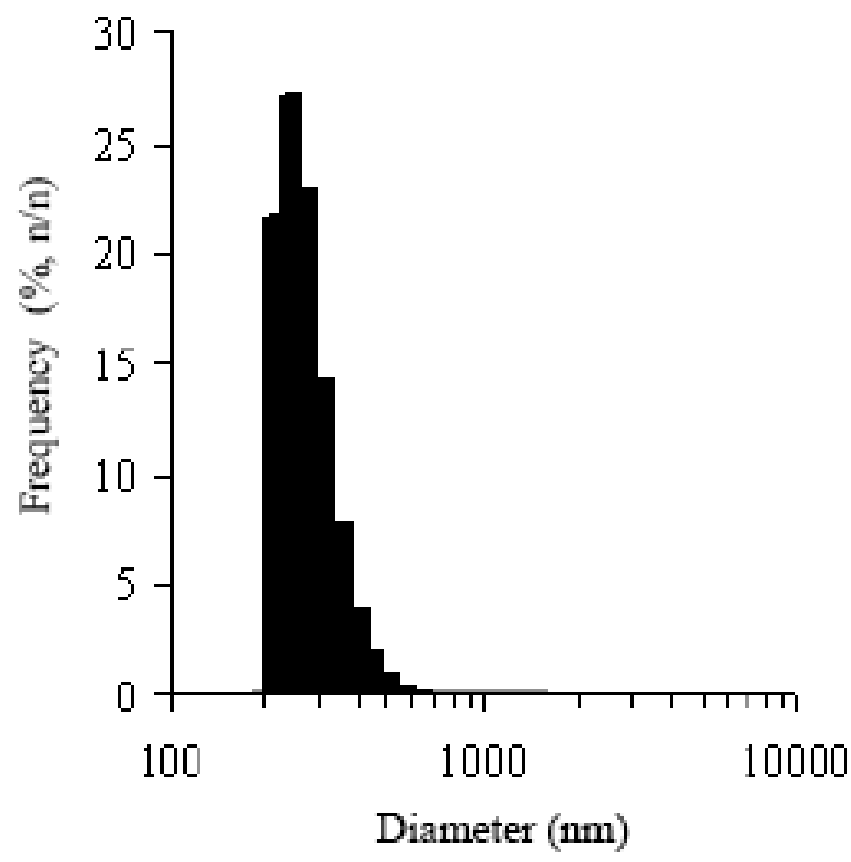

Fig. (4). Particle size distribution of MMC-NP (3). (A) is size distribution in weight, and $(\mathbf{B})$ is size distribution in number.
CM0-L and MMC. CM-MMC was water-soluble. Then, some formulations for the mixture of CM48-L and CM-MMC were tested for the preparation of MMC-loaded nanoparticles (MMC-NP) (Table 3). In each formulation, micro- or nanoparticles could be obtained, indicating that CM48-L acted effectively for the crosslinking reaction during the preparation of nanoparticles. MMC-NP(3) with the smallest size (mean size, $346 \mathrm{~nm}$ ) were obtained at the CM48-L/CM-MMC ratio of 1:5 (w/w). The particle size distribution is shown in Fig. (4). The particles size features of MMC-NP(3) were considered to be useful for passive targeting based on the EPR effect. As to MMC-NP(1) and MMC-NP(2), the drug content was not checked, because their size were too big to undergo the EPR effect. MMC-NP(3) contained MMC at 3.84\% (w/w), which might not be small as drug content because MMC is a highly cytotoxic agent [26, 27]. The release profile of MMC from MMC-NP(3) at $\mathrm{pH} 7.4$ and $37^{\circ} \mathrm{C}$ is shown in Fig. (5). MMC was released from MMC-NP(3) with 47,80 and $92 \%$ at 1,4 and $12 \mathrm{~h}$, respectively. Thus, It was proposed that MMC-NP(3) should act as a nanoparticulate system releasing $\mathrm{MMC}$ fairly fast but gradually. It was suggested that MMC-NP(3) should be useful for tumor targeting and release MMC effectively in the accumulation tumor sites. The in vivo evaluation for such properties as antitumor effects and tissue distribution will be a feature subject for MMC-NP(3).

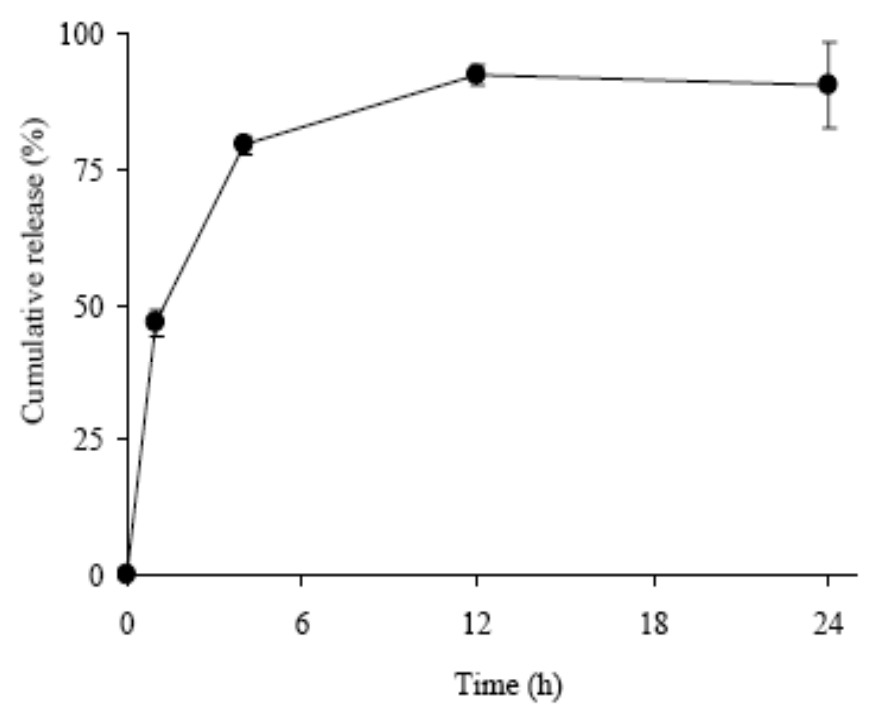

Fig. (5). MMC release from MMC-NP (3) in phosphate buffered saline of $\mathrm{pH} 7.4$ at $37^{\circ} \mathrm{C}$. Each point represent the mean \pm S.D. $(n=3)$. 


\section{CONCLUSIONS}

The degree of deacetylation and molecular weight of $\mathrm{CM}$ could be controlled by a combination of treatment with $10 \%$ $(\mathrm{w} / \mathrm{w}) \mathrm{NaOH}$ and treatment with $5 \mathrm{M} \mathrm{HCl}$ at $40^{\circ} \mathrm{C}$. $\mathrm{CM}$ nanoparticles were prepared by a combination of W/O emulsification and crosslinking with an amide coupling agent (EDC). The formation of nanoparticles was critically affected by deacetylation degree. The degree of deacetylation of $30-40 \%(\mathrm{~mol} / \mathrm{mol})$ was required for the efficiency of nanoparticle formation. The particle size tended to be smaller and averaged less than $400 \mathrm{~nm}$ when $\mathrm{CM}$ with a low molecular weight was used. When MMC-loaded nanoparticles with a size of less than $400 \mathrm{~nm}$ were also obtained by the crosslinking using the mixture of water-soluble CM-MMC conjugate and $\mathrm{CM}$ with a degree of deacetylation of $33 \%$ $(\mathrm{mol} / \mathrm{mol})$ and a molecular weight of 76,000 (CM48-L). These suggest that CM with a high degree of deacetylation and low molecular weight could be useful to prepare CM-drug conjugate nanoparticles by a combination of W/O emulsification and crosslinking with an amide coupling agent.

\section{REFERENCES}

[1] Amano, K.; Ito, E. Eur. J. Biochem., 1978, 85, 97.

[2] Pangburn, S.H.; Trescony, P.V.; Heller, J. Biomaterials, 1982, 3, 105.

[3] Yoshino, T.; Machida, Y.; Onishi, H.; Nagai, T. STP Pharma Sci., 1996, 6, 122.

[4] Takishima, J.; Onishi, H.; Machida, Y. Drug Dev. Ind. Pharm., 2001, 27, 567.

[5] Shu, X.Z.; Zhu, K.J. Int. J. Pharm., 2002, 233, 217.
[6] Kotzé, A.F.; Thanou, M.M.; Luebetaen, H.L.; de Boer, A.G.; Verhoef, J.C.; Junginger, H.E. J. Pharm. Sci. 1999, 88, 253.

[7] Roldo, M.; Hornof, M.; Caliceti, P.; Bernkop-Schnürch, A. Eur. J. Pharm. Biopharm., 2004, 57, 115.

[8] Li, D.H.; Liu, L.M.; Tian, K.L.; Liu, J.C.; Fan, X.Q. Carbohydrate Polymer, 2007, 67, 40 .

[9] Nishimura, S.; Nishi, N.; Tokura, S.; Nishimura, K.; Azuma, I. Carbohydr. Res., 1986, 146, 251.

[10] Yan, C.; Chen, D.; Gu, J.; Hu, H.; Zhao, X.; Qiao, M. Yakugaku Zasshi, 2006, 126, 789.

[11] Song, Y.; Onishi, H.; Nagai, T. Int. J. Pharm., 1993, 98, 121.

[12] Song, Y.; Onishi, H.; Nagai, T. YAKUZAIGAKU, 1993, 53, 141.

[13] Song, Y.; Onishi, H.; Nagai, T. Chem. Pharm. Bull., 1992, 40, 2822.

[14] Song, Y.; Onishi, H.; Machida, Y.; Nagai, T. STP Pharma Sci., 1995, 5,162 .

[15] Hata, H.; Onishi, H.; Machida, Y. Biomaterials, 2000, 21, 1779.

[16] Onishi, H.; Takahashi, H.; Yoshiyasu, M.; Machida, Y. Drug Dev. Ind. Pharm., 2001, 27, 659.

[17] Matsumura, Y.; Maeda, H. Cancer Res., 1986, 46, 6387.

[18] Unezaki, S.; Maruyama, K.: Ishida, O.; Suginaka, A.; Hosoda, J.; Iwatsuru, M. Int. J. Pharm., 1995, 126, 41.

[19] Hata, H.; Onishi, H.; Machida, Y. STP Pharma. Sci., 1999, 9, 115.

[20] Kato, Y.; Onishi, H.; Machida, Y. Carbohydr. Res., 2002, 337, 561.

[21] Ono, S.; Mitsumori, F.; Arata, Y.; Fujiwara, S. Japan analyst, 1977, 26,766 .

[22] Beri, R.G.; Walker, J.; Reese, E.T.; Rollings, J.E. Carbohydr. Res, 1993, $238,11$.

[23] Hoare, D.G., Koshland, D.E. Jr. J. Biol. Chem., 1967, 242, 2447.

[24] Roos, C.F.; Matsumoto, M.; Takakura, Y.; Hashida, M.; Sezaki, H Int. J. Pharm., 1984, 22, 75.

[25] Tanaka, T.; Kaneo, Y.; Iguchi, S. Bioconjug. Chem., 1991, 2, 261.

[26] Hata, T.; Hossenlopp, C.; Takita, H. Cancer Chemother. Rep., 1961, 13,67 .

[27] Kato, A.; Takakura, Y.; Hashida, M.; Kimura, T.; Sezaki, H. Chem. Pharm. Bull., 1982, 30, 2951. 